\title{
Researching Hard-to Reach Populations: Privileged Access Interviewers and Drug Using Parents.
}

\author{
by Nicola Jane Taylor and Jackie Kearney \\ University of Central Queensland; Bolton Institute
}

Sociological Research Online, Volume 10, Issue 2,
< http://umw. socresonline.org.uk/10/2/taylor1.html>
doi:10.5153/sro.1030

Received: 13 Feb 2004 Accepted: 9 Dec 2004 Published: 30 Jun 2005

\begin{abstract}
Accessing drug using populations is notoriously fraught with difficulties for researchers (Gurdin \& Patterson, 1987; Griffiths, Gosspo \& Strang, 1993; Renzetti \& Lee, 1993; Spreen \& Zwaagstra, 1994; Goode, 2000; Elliott et al., 2002). These difficulties are the result of a number of reasons. The main one being that drug use is often illicit and/or illegal which often leads to the stigmatization of drug users within the media and elsewhere and this may ultimately lead to their lives being 'concealed by a veil of ignorance' (Elliott et al., 2002: 172). When one adds to this the fact that the population in question may have even more reason to remain hidden, for example, that they are drug using parents who may wish to conceal their identity as either parent or as drug user, accessing them may be even more complicated for researchers, service providers and policy makers alike.
\end{abstract}

\section{Keywords: Privileged Access Interviewers, Drug Using Parents}

\section{Introduction}

1.1 Accessing drug using populations is notoriously fraught with difficulties for researchers (Gurdin \& Patterson, 1987; Griffiths, Gosspo \& Strang, 1993; Renzetti \& Lee, 1993; Spreen \& Zwaagstra, 1994; Goode, 2000; Elliott et al., 2002). These difficulties are the result of a number of reasons. The main one being that drug use is often illicit and/or illegal which often leads to the stigmatization of drug users within the media and elsewhere and this may ultimately lead to their lives being 'concealed by a veil of ignorance' (Elliott et al., 2002: 172). When one adds to this the fact that the population in question may have even more reason to remain hidden, for example, that they are drug using parents who may wish to conceal their identity as either parent or as drug user, accessing them may be even more complicated for researchers, service providers and policy makers alike.

1.2 Drug using parents often have numerous reasons for keeping their drug use hidden. Fear of losing their children should their drug use become discovered, fear of authority due to past negative experiences, fear of the stigma that is often attached to drug use and fear of the community reaction to both them and their children tend to be among the main reasons cited by drug using parents for keeping their drug use hidden (Kearney \& Taylor, 2001, 2003). Whatever the reasons, the fact remains that drug using parents are even more likely to remain hidden than are other populations of drug user (Elliott \& Watson, 1998; Goode, 2000), and this represents a unique problem for the researcher. One solution to this problem which has been used with varying degree of success is the use of privileged access (or peer) interviewers (Griffiths, 1993; Kuebler \& Hausser, 1997; Elliott et al., 2002). Privileged access interviewers (PAls) are those with access to the population under investigation, usually from within. That is, they are drawn from the sample population itself, so, in this case, would be drug users themselves and ideally, parents.

1.3 This paper discusses the use of PAls within the context of one particular study which aimed to "explore the impact of drug use on the lifestyles and support needs of children and parents in families where one or both parents uses drugs" (Full Research Proposal to NLCB, 1999). Drawing on our own experiences and feedback from PAls themselves in the form of questionnaires submitted to PAls at the end of the study, we discuss the advantages and disadvantages of using PAls in terms of gains to the study, gains to the population of drug using parents we worked with, and issues that arose for us as researchers whilst working with PAls. 
2.1 It has been noted that the number of women using drugs is on the increase and particularly among women of childbearing age. However, service use is predominantly male (ISDD, 1997; Goode, 2000; Kearney \& Taylor, 2001). This particular piece of research conducted with the help of local statutory and voluntary agencies working with children and families, confirmed this national trend. That is, the services were becoming increasingly aware of, and concerned about, the often hidden incidence of drug use within the families they supported. Moreover they were concerned that their current systems did not necessarily support drug using families in general and drug using mothers in particular. Recent records (2000) from one of the services we worked with during this research showed that approximately $15 \%$ of their referrals reported a substance misuse (drug and/or alcohol) component. This figure is, however, misleading, since drug use is particularly hidden within non-drug related services (such as a voluntary family support agency). Of the 147 children from 94 families on our research town's Child Protection Register in October 1997, problems around parental substance misuse were recorded for 50 children (from 39 families - about 42\%). Since then, the register has removed those children in Care Proceedings, so the numbers are difficult to compare. This group are traditionally high in substance misuse. Currently, there are 79 children on the register, of whom $42 \%$ have significant parental substance misuse. Two thirds of these parents misuse drugs (some misuse both drugs and alcohol). If an adjustment were made for those in Care Proceedings, the figure would be significantly higher. Hidden Harm (2003) a report from the government's Advisory Committee on the Misuse of Drugs, estimates that between 250,000 and 350,000 children live in families where one or both parents are in contact with drug services. High levels of separation are also evident, with only $37 \%$ of fathers and $64 \%$ of mothers living with their children.

2.2 A report commissioned by the Department of Health which reviewed research findings relating to parenting capacity and children's needs, identified the lack of research specifically focussing on children of drug using parents (Cleaver, 1999). It was this gap that the research from which this paper is drawn was intended to plug.

2.3 There were a number of aims in this current project. The first was to access service using and nonservice using drug using parents and their children. In itself, this proved a challenge as this is not a particularly easy population to access. For a discussion of the many reasons behind this see elsewhere (e.g. Gurdin \& Patterson, 1987; Griffiths et al., 1993; Renzetti \& Lee, 1993; Spreen \& Zwaagstra, 1994; Goode, 2000; Elliott et al., 2002). A further aim was to actually ask the drug using parents themselves about their lifestyles and any perceived impact of this lifestyle on the lives of their children. Given that drug users generally, and drug using parents specifically, are groups which are subject to many stereotypes (see, for example, Klee, 1998) we wanted to give the parents an opportunity to speak about their lives, their drug use and their beliefs about the impact of their lifestyle on their children as this is an area which has received little attention. A final aim of the study was an assessment of any additional service needs that drug using parents felt would be useful.

\section{Methodology}

3.1 This study aimed to collect data around very broad aspects regarding the impact of drug use on the day-to-day lives and impact on lifestyles of drug using parents and their children, and to further solicit their views about their own needs and any service provisions for them. The fundamental approach adopted was a qualitative one which is well justified in that it allows the researcher to work closely with the researched to present an in-depth look at their lives without deciding for them which are the issues of interest. It also allows for a more reflexive study as it can respond to new issues which are thrown up during the course of the research.

3.2 While policy makers and planners can utilise baseline statistical data around parental drug use, this information is unlikely to present a realistic picture of the number of families affected (given the hidden nature of drug use and/or parental status, and the less than comprehensive nature of records kept by agencies), just as it is unlikely to reflect the lived daily reality of most drug using families. Such data also does not identify their support needs, either met or unmet, or explore the impact of their lifestyle on the wider family members, including children. Whilst a qualitative approach will not necessarily 'fix' all of these problems the adoption of such a paradigm will allow for a reflexive process of discovery that is essential to this research project, and arguably, this topic as a whole. A qualitative approach also has the added advantage of lending itself to sensitive research attempting to access 'hard-to-reach' populations.

3.3 Drug using parents were taken to be, for the purposes of this research, biological parents who used illegal drugs and/or misused prescription drugs. We also interviewed carers who were defined as the legal guardian of children. In terms of this study all the carers we spoke to were the grandmothers of the children they cared for, whose children (i.e. the parents) were using illegal drugs or misusing prescription drugs. 
4.1 The sample was generated through contacts within the Project Advisory Group, contact with parents and carers linked in to specific services (both drug and family), parents and carers who utilise drop-ins (this was the most successful point of access), peer networks and other personal contacts made by the lead researcher (JK). Potential interviewees were given a project information leaflet and were encouraged to discuss the project and what taking part would mean. These leaflets were also widely distributed across local services.

4.2 Once interviews began to be generated from these sources, the snowballing technique was used to pursue other interviews within those networks. This resulted in a total number of 42 adult interviews (not including follow-ups). One focus group, comprising of eight mothers, was completed with families linked to one of the family services involved in this research project. In addition to this eleven interviews were completed by privileged access/peer interviewers and it is with this area of the research that this paper is concerned.

4.3 The difficulties of accessing drug using parents are well documented (e.g. Hogan, 1997; Elliot et al., 1998; Goode, 2000). For this reason we incorporated a degree of flexibility into our original research proposal over the methods of recruitment to be employed. Alternatives were planned for from the very beginning of the study and included the possibility of using focus groups or case studies as well as, instead of, or to support, individual research interviews. We also incorporated PAls into the original conception of this project. During the first six months of the project the researchers contacted numerous specialist and generic services in the geographical area of interest. These included both statutory and voluntary organisations. This provided a general target for accessing drug-using parents. The Project Advisory Group provided the means for accessing a number of specialist agencies where we identified and recruited a number of suitable respondents. However, it was clear from the outset of this project that we would experience difficulties with access and recruitment of participants, and for a number of different reasons. The main reasons for these problems were:

\section{(i) Fears over participation}

4.4 We found drug using parents to be particularly fearful of participating in this research because they were scared of losing their children, felt guilty over their drug use and parenting ability, and had a fear of services. To overcome this we tried to spend more time in drop-ins in order to build rapport and trust with users. Word of mouth was particularly helpful in breaking down some of these barriers (to quote one parents' comments to another "she's alright, she's from a University not social services").

\section{(ii) Family breakdown}

4.5 High levels of family breakdown made it difficult to access wider family networks (i.e.; both parents, grandparents/carers). More than a third of parents were recently estranged (within last 12 months) most commonly because of problematic drug use and/or domestic violence.

\section{(iii) Identity within generic and specialist services - parent or drug user?}

4.6 We found drug use to be particularly hidden within family services and non drug related services (although carers of children of drug users were more easily identified within these services). There were a number of issues around identifying oneself as a drug user and/or parent, depending upon which service was involved. It was common for service workers in drug oriented services to not know their clients family status (i.e. whether they were parents, single, etc), and the same applied to those within family oriented services not necessarily knowing whether their clients were also drug users. This inevitably made contacting drug using parents more problematic as they would often not be known as parents to service workers and commonly chose to keep their status as parent hidden. We overcame this by handing out leaflets to all service users and allowing them to contact us. If they chose not to reveal their parenthood status to the service we arranged interviews with them in a neutral place rather than in the room provided by the service.

\section{(iv) Limitations of access through services}

4.7 We encountered a number of different difficulties in accessing parents through mainstream services. Most statutory services that we worked with did not have an appropriate environment for building rapport between researchers and respondents, such as drop-ins. Contacting respondents via their key worker, or via any third party was mostly found to be unsuccessful. This was the case within our main family service and statutory services such as the Community Drugs Team (CDT). We concluded that face-to-face contact and rapport building was our most valuable means of access, e.g. via drop-ins. This form of access proved 
most useful because; (i) it is easier to do than through mainstream sources; (ii) our target population often use a range of services anyway, and (iii) it allowed the researchers to assuage potential interviewees' fears. These fears generally came from a mistrust of 'authority figures' and this was compounded by a fear of losing their children should their status as both drug users and parents be identified. Some services were also very protective about access to their clients, in terms of the clients' potential vulnerability.

4.8 Drug using parents who did not use services proved more problematic to contact and access. This population is particularly difficult to access for several reasons. Firstly, they are not service users and therefore access through established services and drop-ins is virtually non-existent. They are the most hidden in the drug using population. Secondly, it is important to keep in mind the known characteristics of drug users who access services, as this tells us something about non-service users. Mothers (and women in general) are poorly represented amongst drug service users, which is in contrast to their use of other services such as primary care or family services so contacting drug using mothers in this way was made more difficult (Goode 2000).

4.9 The notion of 'successful' drug users was considered in terms of the methods used for accessing nonservice users, a population we know little about. There are non-service users who may be deemed chaotic, and difficult to access because of their erratic and inconsistent lifestyle and drug use. There are also those who do not access services because they do not need or want to. These parents could be seen as even more difficult to access since their differing status may inhibit or hide their drug use behind their acceptable identity.

4.10 It was in this area of non-service use that PAls became most useful. More than half of the interviews in this study by PAls were non-service using drug using parents. However, the use of PAls throughout this study was not without problems and it is to a discussion of the process of working with PAls that we now turn in order to assess the advantages, disadvantages, problems and possible remedies of working with PAls.

\section{Privileged Access Interviewers}

5.1 The PAls were recruited through advertisements placed in services for appropriate stable or ex-users. Initially, three interviewers were recruited from a voluntary drugs service. Two were ex-drug users, one a stable methadone user and one an ex-stimulant user. Both were in their mid-20s and both were volunteers at the service they were contacted through. Both were also parents. The third PAI recruited through this service was a voluntary worker at that service and had no personal history of drug use.

5.2 From the group initially recruited, only one successfully completed the training and interviews with parents. One became quite vulnerable during the training due to non-drug related circumstances, and was encouraged to work as a finder instead (that is to introduce the researcher to other members of their peer network). The third PAI disappeared following the training, with the equipment and some payment vouchers. A number of unsuccessful attempts were made to contact this person. The third interviewer was very successful and completed five interviews, of which four were with non-service users. Two more PAls were recruited towards the end of the first year of the project. They successfully completed six interviews between them. One of these interviewers was a stable methadone user and carried out two important nonservice user interviews with drug using parents.

5.3 After potential PAls indicated their interest in the project they were asked about their own backgrounds and experiences. It was then explained to them that the data gathering stage of the research would take place some weeks into the future and the time in between was used by the researchers to get to know the potential PAls. Their stability and suitability was also discussed with the drug service staff who had known them for a number of months. Following recruitment the PAls were trained and given advice about the projects' aims and objectives. This involved working with them for approximately four hours to address issues such as confidentiality, interview technique, dealing with interviewees who become distressed, and, safety. Following training the PAls were free to conduct their own interviews. We stayed in close touch with the PAls throughout the project, regularly visiting them to talk to them about their experiences and support and debrief them if necessary, and to provide them with necessary tapes, vouchers and payment.

5.4 During the planning of this project the use of PAls were considered only to facilitate access. However, as the project progressed and the researchers met and worked with the PAls during training it became clear that they could add to the project in a further way. This was essentially by contributing to the design of the interview. Whilst talking with the PAls it became clear that there were certain topics of interest that the researchers had not considered (for example, the time and expense many drug using parents went to in order to attend drug counselling sessions). By listening to the PAls we were able to add a couple of topics to the interview schedule. Arguably these topics would have become apparent after the early interviews and would thereafter have been incorporated into the later interviews but by listening to the PAls we were able to 
5.5 Unfortunately, there was no opportunity to bring the PAls together to discuss their experience on the project, which had been identified in previous research as an important mechanism in supporting them and their work (Elliott \& Watson, 1998; 2001). However, we did give all our PAls a questionnaire which asked them about their experiences as PAls. Some of our PAls completed the questionnaire after every interview and some completed them when they had concluded work on the study. The questionnaire asked the PAls to list both positive and negative experiences they had encountered whilst working on this study.

5.6 Positive experiences were varied and included feeling rewarded, feeling worthwhile, feeling important, and generally enjoying the experience. PAls also asserted that they felt trusted by those they interviewed and experienced a high level of honesty from users who were willing to talk in detail 'about what they knew and prescribed.' Many of our PAls also believed that they gained confidence from the process of interviewing others with similar problems to themselves. This was especially the case for one PAI who felt encouraged by 'drug users actively seeking me out to take part in the research,' and for another PAI who was surprised and gratified to find out the high level of knowledge that users often have about certain issues, for example, that 'a lot of users know how to administer first aid.'

5.7 On the negative side the PAls in this project reported very similar themes such as feeling threatened by an air of violence and actively receiving threats. Another form of threat identified was that of having to go into the active drug using community to find interviewees who were not readily accessible by other means. Many PAls brought up issues concerning interviewing people they knew such as knowing that interviewees are lying about certain issues; dealing with potential threats to confidentiality by knowing their interviewee well, and feeling let down that their friends did not trust them in this instance. Lastly, PAls noted that some of their interviewees were not interested in the interview or the research and were only there for the payment. This struck a particular chord with our PAls as they were, on the whole, incredibly committed to the project themselves and were not happy when faced with someone who did not share that level of commitment.

5.8 The PAls in this study were invaluable in that they were able to establish rapport and trust with their interviewees in a way that we, as outsiders and as 'university' researchers, were unable to do. This is not to be taken lightly as working with drug using parents arguably depends more on trust than with other populations given the fear of participation which exists. This may have led to them gathering fuller, and more open, accounts of the lives of drug using parents. Again, the value of this to this particular project cannot be stressed enough. Given that our remit was to "explore the impact of drug use on the lifestyles and support needs of children and parents in families where one or both parents uses drugs" (Full Research proposal to NLCB, 1999) successful completion of this project depended upon open and frank discussions with participants concerning a consideration of the impact of their lifestyles on them and their children. Without full trust and open interviews an analysis of this impact would have been impossible.

5.9 In addition the PAls were able to contact participants from within their own networks and thus widen participation in this project to non-service users and/or those who were not immediately identifiable as drug users which were the most difficult group to access in this study. Ultimately the PAls gained access to networks that we could not given the time frame in which we had to work. It is conceivable that an experienced field worker may have achieved similar results given a realistic time frame within which to make contacts and establish trust and rapport. However it is also conceivable that given status differences (real, implied, or assumed) between those seen as 'university staff' and those from within drug using cultures that a researcher would not be able to access non service-using drug-using parents to the same capacity.

\section{Discussion}

6.1 One of the main issues which arose throughout this research was trust. This is in keeping with others experiences of working with PAls (e.g. Elliot et al., 2002). Trust was an issue here on all sides of the equation. For instance, trust from researchers to PAls which can often be abused, for example in the case of one of our PAls who disappeared with a number of vouchers and recording equipment. Steps can be taken to limit the amount of damage done, such as only issuing PAls with a small number of vouchers. This has two advantages in that it limits any potential damage, but it also means that the researchers and PAls have to stay in touch every two or so interviews conducted in order to physically get the resources needed to the PAls. This allows the researcher to debrief the PAI and deal with any problems which may arise very early, such as spotting potential vulnerabilities in the PAI which may be exacerbated by their exposure to active drug users.

6.2 Trust is also an issue from the PAl to the researcher. Many of our PAls wanted reassurances that they were not being used by us to access their peer groups in order to gain privileged information which we would then misuse. At the time of the research project this appeared a fairly straightforward issue to 
negotiate. We were sure of our motives and explained them to the PAls. With the benefit of hindsight, and the misuse of some of our findings by the media, we now realise that this promise is relatively dificult to maintain. Involvement in any future projects utilising the expertise of PAls would account for this in the training of PAls where we would be able to explain this in more detail. Our PAls also reported that trust was an issue for them when conducting interviews, that is, getting their interviewee to trust them. This presented problems when the PAI knew their potential interviewee and felt that they did not trust them, and many PAls reported feeling let down when interviewees they considered friends clearly lied to them during the interview process. Having the support of service providers proved important at this point. We were able to notify service providers that interviews were taking place and use their premises. This ensured that any participants, PAls or otherwise, could access the counselling services available should they become distressed as a result of the interview and need to do so.

6.3 Perhaps the trust issues raised throughout this project can meaningfully be considered in terms of power. It is widely acknowledged within social science research that the relationship between researcher and researched is not necessarily an equal one and that a number of factors may mediate researcherresearched interaction, one of which is the amount of power (perceived, or actual) that the researcher has over their participants (e.g. Oakley, 1979). Indeed, it has traditionally been accepted that the researcherresearched relationship is one between 'powerful researcher' and 'powerless-researched' (D'Cruz, 2000). Whilst recent research has begun to question such simplistic demarcations (e.g. D'Cruz, 2000) there still remains an awareness of the disparity between researcher and researched but it may be that this actually revolves around negotiation and access to sites of power and knowledge rather than the researcher simply having more power than the researched based on social status, education level etc. Given that this study involved the participation of a stigmatised group who were acutely aware of their stigmatisation both as drug users and as drug using parents, it may be that such issues were amplified. For example, the researchers may well have been perceived to have power over the researched whilst the researched were often seen, by the researchers, as having a power of their own, i.e. the power to grant or restrict entry into the population under study. This may begin to explain why PAls also found issues with trust. As researchers we expected to encounter problems with our sample trusting us but because PAls identify themselves with the sample group, they did not. This may have been an oversight on our behalf and any future studies incorporating the use of PAls needs to address this matter during training with the PAls. Given that this perceived mistrust upset the PAls it might also be worth considering debriefing them on this topic specifically and possibly ensuring the availability of relevant support mechanisms for them such as service-workers who would be willing to discuss this with them.

6.4 A problem that we felt as researchers was a distance from the data collected and a lack of control over the data collected. Our experiences here closely mirror those of Elliott et al. (2002) in that whilst we found that our PAls clearly were able to access a population that we could not, the fact that we felt distanced from the data they were collecting, and from this population as a whole, was an issue of some concern for us. Our concerns were on two different levels. One was that we were becoming 'strangers' to our own project and the other was the issue of the reliability and validity of the data collected. This leads to another, closely related point. A huge concern we have with the use of PAls arises in terms of the data collected. There is an opportunity to misuse PAls as a cheap resource that can gain access to hidden populations and interview them cheaply. Notwithstanding the moral and ethical issues that arise in such a circumstance, there is also the impact that this may have on the quality of the work undertaken. We would strongly argue that for this reason PAls need to be one part of the research process and not all of it and/or a number of checks and balances must be put into place prior to the use of PAls to make sure that they are not exploited and to check the quality of their work. For example, we transcribed the PAI interviews ourselves and cross-checked them between two researchers in order to assess their validity and reliability. This also had the further advantage of minimising the sense of distance we felt from the data collected.

6.5 The welfare of any PAls involved in this study was an issue of concern for us. We were very aware of our own limitations here - we are not counsellors and are not necessarily equipped to deal with any problems that may arise. There is the risk that PAls may become unstable simply by being around active drug-users and active drug-using culture (Elliott et al., 2002) and steps have to be taken to mediate this. In order to begin to deal with this, we stayed in close touch with a number of drug and social workers and solicited their advice before taking on PAls, during the training of the PAls, and throughout the rest of the PAls involvement in the study. If necessary we would contact the PAls case worker and ask them to debrief the PAI. In addition, if we suspected that a PAI was at risk we would encourage them to leave the project or, if appropriate change their role within the project, and/or seek help depending on circumstances. One particular PAI who became vulnerable through non-drug related circumstances was encouraged to become a 'finder' for us as opposed to an interviewer, and put us in touch with potential interviewees. Many of the potential problems with PAls becoming vulnerable due to participation in a project such as this were lessened in some cases because we recruited both PAls and subjects through established services who supported our work. We were therefore able to draw on their expertise, if necessary, to debrief PAls or to 
otherwise work with them. This was a crucial part of the study and its importance in maintaining the welfare of PAls can not be overstated.

6.6 A good number of our PAls became very committed to the project and it became clear as the project progressed, that it meant a lot to them to be involved and to be trusted. In this way it would be unfair and ethically questionable to simply cut PAls off after the project had finished. We therefore had an exit strategy in place to deal with this. We kept in touch with our PAls for a number of months after they had finished interviewing for us, and finally made copies of the report for all services involved and let our PAls (and for that matter or participants) know that where they could access copies of the report. Had the budget allowed we would have made individual copies of the report for all PAls and should we be in this position again will ensure that this is fully considered in any budgetary proposal. We continue to inform all involved in the study, and particularly the PAls, of anything published concerning the study. Again, the fact that we recruited through, and often worked in, established drug services helped here in that we could draw on the experience of drug workers for advice if needed. We also encountered a number of PAls who felt that working on the project had given them a significant social outlet and we were loathe to simply end this. Accordingly we would then direct them to other social activities within the established services rather than simply remove one of their important social outlets.

\section{Conclusion}

7.1 We learnt, and gained, a great deal from our collaboration with PAls on this project. The most obvious advantage was being able to access a population denied to us as researchers. Linked to this was the rich data that the PAls often gathered as they were able to interact with their interviewees in ways which we were not, being more accustomed to the cultural nuances than us. The main disadvantages we came across were the distance we often felt from the study/data as a result of using PAls; the time consuming nature of working with PAls who need training and monitoring throughout the study, and the potential for PAls to become vulnerable because of the work we had asked them to undertake.

7.2 On reflection, however, our use of PAls clearly contributed to our study in a very unique way and contributed to our own learning curves considerably. Overall we would recommend the use of PAls when working with hidden or hard to access populations as long as it is given much thought and a lot of work is done before they are recruited. For example, a number of safeguards need to be instituted such as setting up training systems and working with professionals to establish careful guidelines for their safety and welfare. We would also argue that it is also imperative that if and when PAls are used they are not the sole collectors of data in order to maintain the quality of the research and to ensure that they are not abused as a cheap resource by the research community at large.

7.3 In terms of future directions, a focus on problematic drug use could have added to this study. It would have enabled us to explore local data and projections to estimate how many parents might have problematic drug use. On the other hand, identifying and accessing a small number of stable non-service drug using parents is essential in balancing the picture as a whole about drug users' lifestyles, and particularly those who are parents. Whilst it may have limited service implications, it challenges some of the stereotypes and stigmatised reactions to drug using parents, and drug users per se. This can also inform policy (and therefore some service provision) meaning that challenging these stereotypes is as important and as valid as collating the experiences of service users. It also encourages our recognition about the context of most problematic drug use, and indeed how we define problematic in the first place.

\section{References}

ACMD. (2003) Hidden Harm: Responding to the needs of children of problem drug users; The Report of an Inquiry by the Advisory Council on the Misuse of Drugs. London: Home Office.

CLEAVER, H., Unell, I., \& Aldgate, J. (1999) Children's Needs - Parenting Capacity: The Impact of Parental Mental illness, Problem Alcohol \& Drug Use, and Domestic Violence on Children's Development. The Stationary Office: London.

D'CRUZ,H. (2000). 'Social Work Research as Knowledge/Power in Practice,' Sociological research Online, vol 5 (1): http://socresonline.org.uk/5/1/dcruz.html

ELLIOTT, E., Watson, A., \& Harries, U. (2002) 'Harnessing Expertise: Involving Peer Interviewers in Qualitative Research with Hard-to-Reach Populations,' Health Expectations, Vol. 5, pp.172-178. 
GRIFFITHS, P., Gosspo, M., \& Strang, J. (1993) 'Reaching Hidden Populations of Drug Users by Privileged Access Interviewers: Methodological and Practical Issues,' Addiction, Vol. 88, pp. 1617-1626.

GOODE, S. (2000) 'Researching a Hard-To-Access and Vulnerable Population: Some Considerations on Researching Drug and Alcohol-Using Mothers,' Sociological Research Online, vol. 5 (1) :

<http://socresonline.org.uk/5/1/goode.html>

GURDIN, J., \& Patterson, C. (1987) 'The Problem of Sample Frame in Populations Called Deviant: The case of Methadone-Maintained Women and their Infants,' Journal of Community Psychology, Vol. 15, No. 4, pp. 459-470.

ISDD. (1996) UK National Report for the European Monitoring Centre for Drugs and Drug Addiction, 1996. London: Institute for the Study of Drug Dependence

KEARNEY, J., \& Taylor, N. (2001) The Highs \& Lows of Family Life. Project Report IPHRP, University of Salford.

KLEE,H. (1998) Drug-Using Parents: Analysing the Stereotypes,' International Journal of Drug Policy, Vol. 9, pp. 437-448.

KUEBLER, D. \& Hausser, D. (1997) 'The Swiss Hidden Population Study: Practical and Methodological Aspects of Data Collection by Privileged Access Interviewers,' Addiction, Vol. 92, No. 3, pp. 325-334.

OAKLEY,A. (1979). From Here to Maternity. Penguin. Harmondsworth.

RENZETTI, C., \& Lee, R. (editor) (1993) Researching Sensitive Topics. Newbury Park: Sage.

SPREEN, M., \& Zwaagstra, R. (1994) 'Personal Network Sampling, Outdegree Analysis and Multilevel Analysis: Introducing the Network Concept of Studies of Hidden Population,' International Sociology, Vol. 9, pp. 475-91. 